\title{
Range of Thresholds Used for Treatment of Neonatal Hyperbilirubinemia at Different Gestational Ages across Neonatal Units in Great Britain
}

\author{
Puneet Kumar Arora $^{1 *}$, Sindhu Mohandas ${ }^{2}$, Deborah Ridout ${ }^{3}$, Narendra Aladangady ${ }^{1,4}$ \\ ${ }^{1}$ Neonatal Unit Homerton University Hospital, London, UK; ${ }^{2}$ Department of Paediatrics, Queens Hospital, Essex, UK; ${ }^{3}$ Institute of \\ Child Health, Department of Paediatric Epidemiology and Biostatistics, London, UK; ${ }^{4}$ Barts and the London School of Medicine and \\ Dentistry, Queen Mary, University of London, London, UK. \\ Email: *docarorap@gmail.com
}

Received September $5^{\text {th }}, 2011$; revised October $15^{\text {th }}, 2011$; accepted October $25^{\text {th }}, 2011$.

\begin{abstract}
Objectives: To review the range of thresholds used for treatment of neonatal jaundice at different gestational ages across neonatal units in Great Britain. To investigate the time at which the threshold values plateau, in terms of hours after birth, for various gestational ages. Methods: We contacted 72 neonatal units in Great Britain and enquired about the unit guidelines for management of neonatal jaundice. We requested a copy of the guidelines and jaundice action charts used. Levels for treatment with phototherapy and exchange transfusion for various times after birth and for different gestational ages were extracted and the data was transferred to an Excel spreadsheet. Identical values were excluded so that there was no duplication of charts. The data was analysed to explore the variation in charts used and the time at which the threshold value reached a plateau was recorded for each chart. Results: Of the 72 units contacted 46 responded with charts. Four neonatal units were using formulas and one hospital was using separate chart for every gestation. The data displayed wide variation in treatment levels (phototherapy and exchange transfusion) at 12 to 168 hours after birth in the three gestational groups studied (28, 32 and 37 weeks). For a term neonate at 72 hours of age the threshold to commence phototherapy varied between 220 - 370 micromol/l and the exchange transfusion threshold varied between 300 - 510 micromol/l. A wide variation in practice was seen for all three gestations. The median plateau time was also analysed and for phototherapy this corresponded to 72 hours for all three gestations. For exchange transfusion data the median time of plateau was highest for the term babies (72 hours) and lowest for 32 weeks gestation (48 hours). There was no reference of evidence quoted in the jaundice action charts surveyed. Conclusions: Jaundice action charts reviewed in our study showed significant variation in the threshold for treatment of neonatal jaundice. Both the studied parameters (variation in threshold and the median time to plateau) point towards the fact that the charts being used in the neonatal units are not evidence based and need modification. With the lack of standard treatment guidelines for this common neonatal problem, it is likely that neonatal units are either under or over treating a significant number of babies.
\end{abstract}

Keywords: Neonatal Jaundice, Phototherapy, Exchange Transfusion

\section{Introduction}

Jaundice comes from the French word jaune, which means yellow. Neonates are at higher risk because of an immature blood-brain barrier, and the susceptibility of the brain cells to damage by bilirubin [1]. Various treatment modalities have been used to treat neonatal hyperbilirubinemia but phototherapy and exchange transfusion remain the mainstay of treatment of neonatal jaundice.
In their original description of phototherapy, Dobbs and Cremer [2] demonstrated that exposure of newborns to sunlight would lower the serum bilirubin level. Now phototherapy is an established and effective treatment for neonatal jaundice [3]. Although it is a relatively easy to provide phototherapy, it is not without potential side effects. Prolonged exposure to bright ambient light may damage cone photoreceptors [4] and increase the inci- 
dence of retinopathy of prematurity [5]. When infants are exposed to prolonged phototherapy, they may develop grayish-brown discoloration of the skin (bronze baby syndrome) [6]. Purpura and bullous eruptions have been described in infants with cholestatic jaundice receiving phototherapy $[7,8]$ and severe blistering and photosensitivity during phototherapy has been seen in infants with congenital erythropoietic porphyria $[9,10]$.

History of exchange transfusion dates back to nineteen twenties when it was first performed and described by Harts in 1924 [11,12]. Death associated with exchange transfusion has been reported in approximately 3 in 1000 procedures $[13,14]$. Mortality rates attributable to exchange transfusion ranged from $0.65 \%$ to $3.2 \%$ in studies performed in the 1960s [15] and from $0.4 \%$ to $3.2 \%$ during the 1970s and 1980s [16]. Causes of death ascribed to exchange transfusion included cardiovascular collapse during the procedure, and the subsequent complications of necrotizing enterocolitis, bacterial sepsis, and pulmonary hemorrhage. Adverse events remain common after exchange transfusion. Some complications are as severe as, or worse than, the bilirubin encephalopathy the exchange transfusion was intended to prevent. These severe complications must be balanced against the benefits of lowering serum bilirubin.

If not appropriately treated neonatal jaundice may be associated with lower IQ [17] and deafness [18]. Babies with neonatal jaundice are known to have significantly more neurological, motor and developmental difficulties and caused greater maternal concern [19].

There is no reported national or international guideline for management of neonatal jaundice, which is a common neonatal problem with potentially serious effects. Our objective was to review the range of thresholds used for treatment of neonatal jaundice at different gestational ages across neonatal units in Great Britain and to investigate the time at which the threshold values plateau, in terms of hours after birth, for various gestational ages (24 - 27, 28 - 31, 32 - 36 and term).

\section{Methods}

We contacted neonatal units in different parts of Great Britain and enquired about the unit guidelines for management of neonatal jaundice. A copy of the unit guideline and chart was collected.

Serum bilirubin levels for initiating treatment with phototherapy and exchange transfusion at different gestational ages (28 weeks, 32 weeks and term) were extracted. The data was transferred to an excel spreadsheet. Identical values were excluded so that there was no duplication of charts.

Research ethics committee approval was not required as no human subjects were involved.

\section{Statistics}

The variation in treatment levels between charts, at 12 to 168 hours from birth for gestational groups: 28 weeks, 32 weeks and term were investigated. Also the time in hours after birth at which the threshold value reached a plateau was recorded for each chart. All data was summarized using median and range.

\section{Results}

72 neonatal units were contacted out of which 46 responded with jaundice action charts. Four neonatal units were using formulas and one neonatal unit was using separate chart for every gestation. Two units were using charts according to weight of the baby and one unit had the gestational age on the $\mathrm{X}$ axis. There was no reference stated for the bilirubin levels considered for treatment in the charts reviewed.

As seen in Table 1 the maximum variation in charts with regards to treatment values was for term babies. Lesser variation was seen in the other two gestational groups with the least being in the 32 week gestation. None of the charts gave any advice regarding the direct component of total bilirubin.

\subsection{Threshold for Initiating Phototherapy for Term Infants}

The range of values at which initiation of phototherapy is recommended was widest at 12 hours of age (median 110 $\mu \mathrm{mol} / \mathrm{l}$ and range $60-310 \mu \mathrm{mol} / \mathrm{l})$. One of the charts gives $310 \mu \mathrm{mol} / \mathrm{l}$ as a cut of for treatment from 12 hours onwards. There continues to be a wide range of treatment values from 12 to 72 hours which narrows slightly after $72 \mathrm{hrs}$ (Figure 1). After 72 hours 350 - $370 \mu \mathrm{mol} / \mathrm{l}$ is a common threshold to initiate phototherapy.

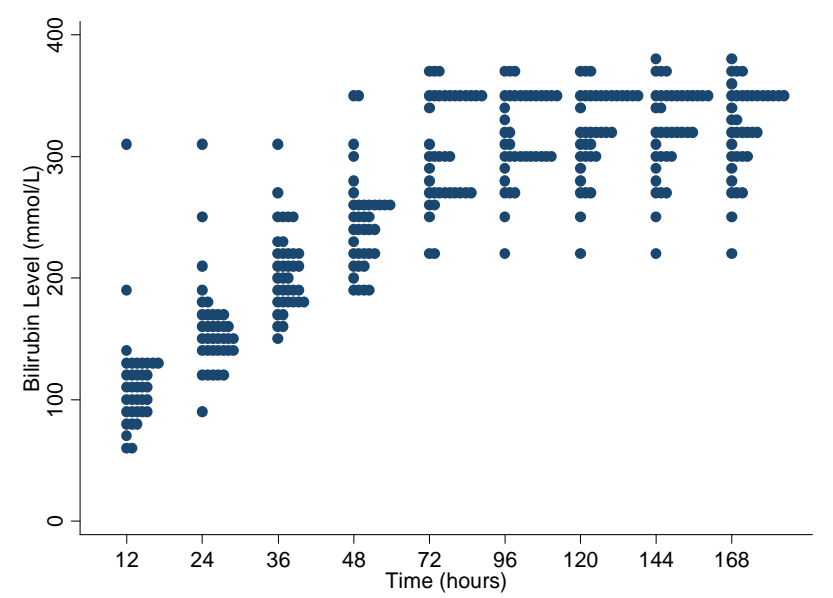

Figure 1. Variation in bilirubin levels for phototherapy in term babies. 


\subsection{Threshold for Performing Exchange Transfusion for Term Infants}

The values at which exchange transfusion is recommended in term babies shows a very wide range especially at 12 hrs (median $180 \mu \mathrm{mol} / \mathrm{l}$, range $60-450 \mu \mathrm{mol} / \mathrm{l}$ ) and at 24 hrs (median $277.5 \mu \mathrm{mol} / \mathrm{l}$, range 110 - $500 \mu \mathrm{mol} / \mathrm{l}$ ) (Figure 2). After 72 hours although the variation decreases but there seems to be three levels (350, 400, $430 \mu \mathrm{mol} / \mathrm{l}$ ) commonly used as cut off for exchange transfusion on many charts.

\subsection{Threshold for Initiating Phototherapy at 32 Weeks Gestation}

The variation is least at 12 hours of age and progressively increases till 72 hours where it becomes constant. At 12 hours the range is between $70-120 \mu \mathrm{mol} / \mathrm{l}$ with a median value of $95 \mu \mathrm{mol} / \mathrm{l}$. The range increases to 150 $320 \mu \mathrm{mol} / \mathrm{l}$ with a median of $232.5 \mu \mathrm{mol} / \mathrm{l}$ at 168 hours. After 72 hours many units seem to be using values between $220-260 \mu \mathrm{mol} / \mathrm{l}$ but the range remains wide (Figure 3).

\subsection{Threshold for Performing Exchange Transfusion at 32 Weeks Gestation}

This set of value appears to be more consistent compared to the others. The range is least at 12 hours and gradually increases by 168 hours of age. The range of values does increase with the age of the baby being greatest after 144 hours of age. The range at 12 hours is $115-180 \mu \mathrm{mol} / \mathrm{l}$ with a median of $160 \mu \mathrm{mol} / \mathrm{l}$. Many units are using levels around $290 \mu \mathrm{mol} / \mathrm{l}$ as a threshold for intervention after 24 hours of age (Figure 4).

\subsection{Threshold for Initiating Phototherapy at 28 Weeks Gestation}

The variation is lower at the beginning of life and becomes greater by 144 hours of age. At 12 hours of age the median value is $85 \mu \mathrm{mol} / \mathrm{l}$ and the range is between 60 $\mu \mathrm{mol} / \mathrm{l}-180 \mu \mathrm{mol} / \mathrm{l}$. At 168 hours of age the median value is $170 \mu \mathrm{mol} / \mathrm{l}$ with a range of $120-330 \mu \mathrm{mol} / \mathrm{l}$ (Figure 5).

\subsection{Threshold for Performing Exchange Transfusion at 28 Weeks Gestation}

28 week exchange transfusion graph (Figure 6) shows very wide variation through out. The range is high at 12 hours of age, narrowing at 48 hours and then again progressively increasing till 168 hours of age. At 168 hours the median is $260 \mu \mathrm{mol} / \mathrm{l}$ with a range of $200-390$ $\mu \mathrm{mol} / \mathrm{l}$.
Table 1. Number of different charts obtained after excluding duplications.

\begin{tabular}{ccc}
\hline & Phototherapy & Exchange transfusion \\
\hline Formula & 4 & 4 \\
37 weeks & 37 & 29 \\
32 weeks & 20 & 14 \\
28 weeks & 29 & 20 \\
\hline
\end{tabular}

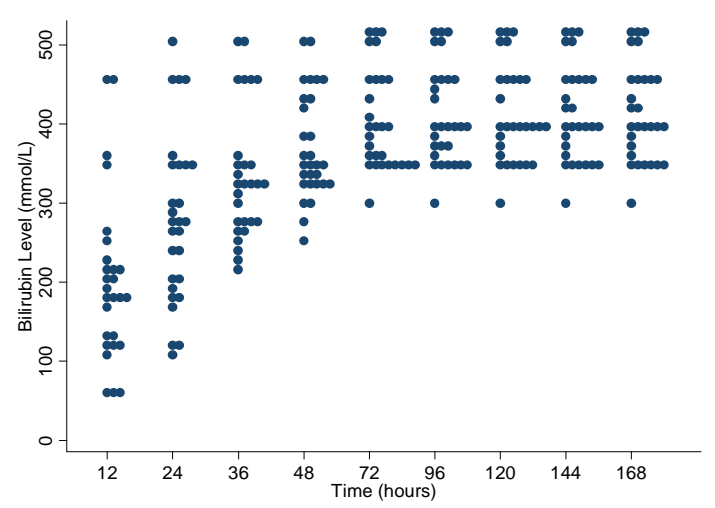

Figure 2. Variation in bilirubin levels for exchange transfusion in term babies.

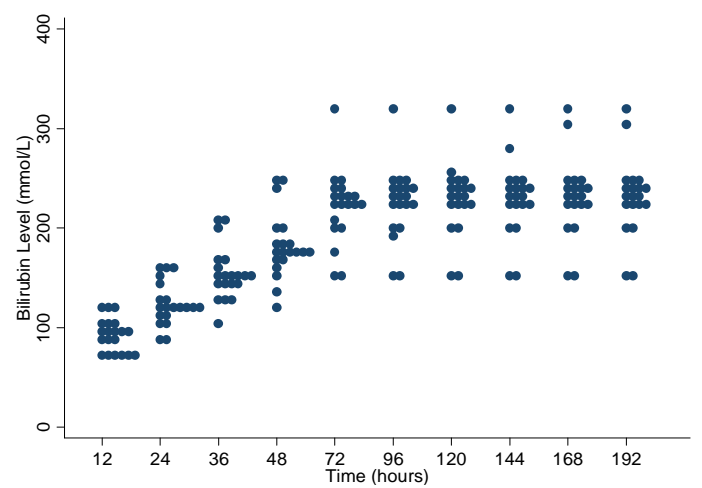

Figure 3. Variation in bilirubin levels for phototherapy in 32 weeks gestation.

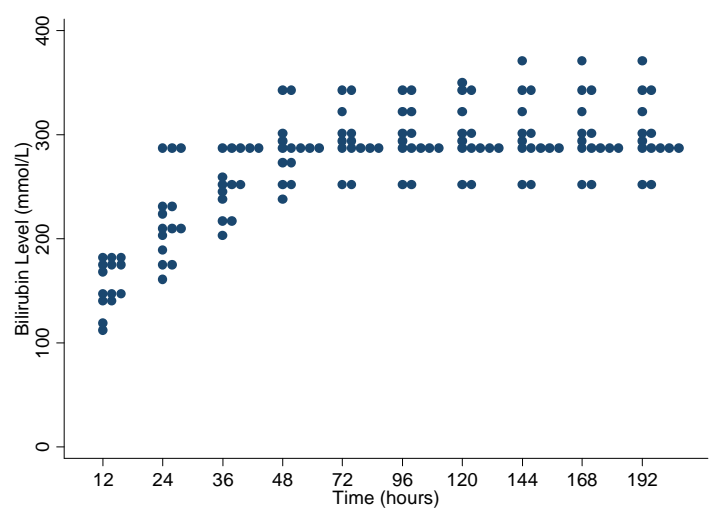

Figure 4. Variation in bilirubin levels for exchange transfusion in 32 weeks gestation. 


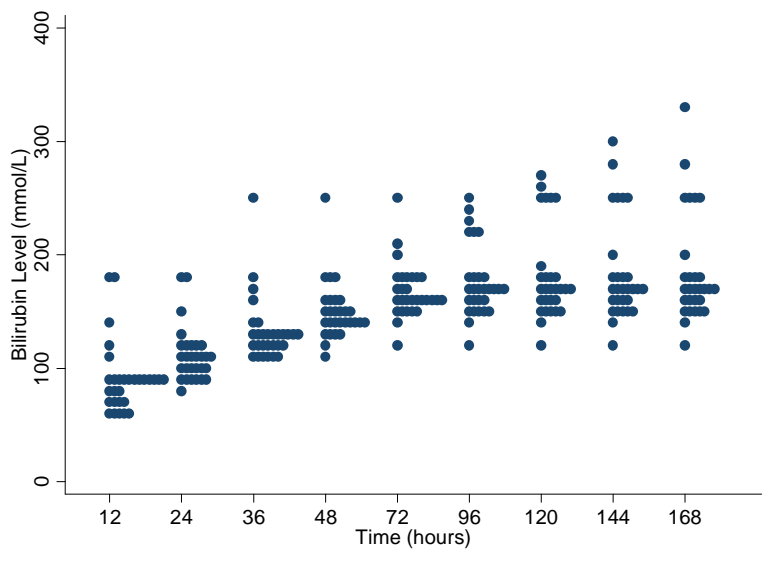

Figure 5. Variation in bilirubin levels for phototherapy in 28 weeks gestation.

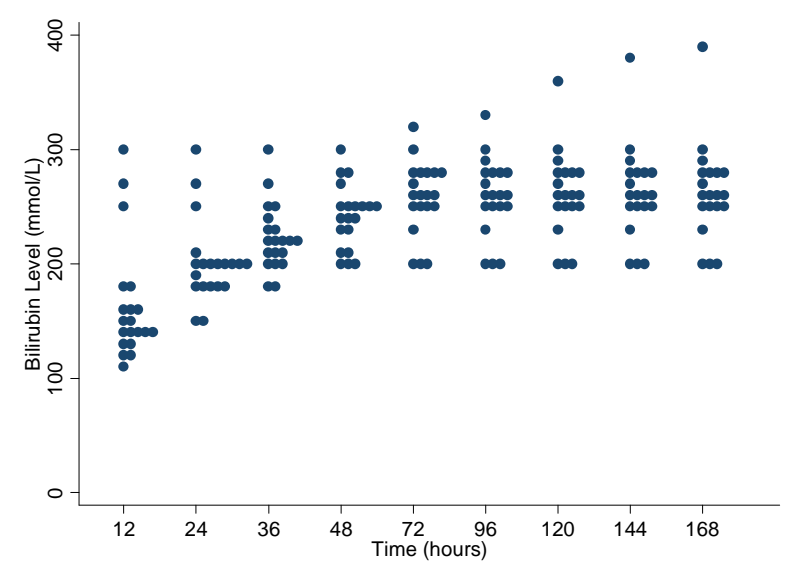

Figure 6. Variation in bilirubin levels for exchange transfusion in 28 weeks gestation.

\section{Plateau Time Summary}

On scrutinizing the bilirubin charts it was noticed that for most of them there appeared to be a plateau in the relationship between threshold for treatment and hours after birth. Tables 2 and 3 show the median and the most frequent plateau time for each gestational group for both phototherapy and exchange transfusion.

\subsection{Phototherapy}

The median plateau time for phototherapy remains 72 hours for all gestations. This is the time when most of the slopes tend to become more horizontal indicating a slower rise in bilirubin levels and higher tolerance for bilirubin toxicity.

\subsection{Exchange Transfusion}

There was no pattern noted for the median time to plateau for exchange transfusion in various gestations. As seen in Table 3 the median time to plateau was longest
Table 2. Time at which the bilirubin level reached a plateau in phototherapy charts.

\begin{tabular}{cccc}
\hline Gestation & Median & Range & $\begin{array}{c}\text { Most Frequent } \\
\text { Plateau Time }\end{array}$ \\
\hline 28 weeks & 72 hours & 12 to 168 hours & $\begin{array}{c}7 / 29(24 \%) \text { at } 72 \text { hours } \\
8 / 29(28 \%) \text { at } 96 \text { hours }\end{array}$ \\
32 weeks & 72 hours & 48 to 168 hours & $\begin{array}{c}9 / 20 \text { charts }(45 \%) \text { at } 72 \\
\text { hours }\end{array}$ \\
& & & \\
37 weeks & 72 hours & 12 to 168 hours & $18 / 37(49 \%)$ at 72 hours
\end{tabular}

Table 3. Time at which the bilirubin level reached a plateau in exchange transfusion charts.

\begin{tabular}{cccc}
\hline Gestation & Median & Range & $\begin{array}{c}\text { Most Frequent } \\
\text { Plateau Time }\end{array}$ \\
\hline 28 weeks & 60 hours & 12 to 168 hours & $8 / 20(40 \%)$ at 72 hours \\
32 weeks & 48 hours & 24 to 144 hours & $8 / 14(57 \%)$ at 48 hours \\
37 weeks & 72 hours & 12 to 144 hours & $9 / 29(31 \%)$ at 72 hours \\
\hline
\end{tabular}

for term babies and shortest for 32 weeks gestation babies.

\section{Discussion}

Jaundice is one of the most common and potentially serious problems encountered in newborn babies. Around $50 \%$ - 80\% babies will develop jaundice sometime in the first week of life [20]. Most cases are benign and do not need any treatment. Because of the potential toxicity of bilirubin, neonatal jaundice should be appropriately monitored and treated. Most of the guidelines focus on prevention of bilirubin encephalopathy or kernicterus. Kernicterus although very rare in current clinical practice is a preventable cause of brain damage. There are no data to suggest the gradation of impact of various levels of bilirubin on the central nervous system.

Our study demonstrated lack of uniformity and wide variation in treatment guidelines for phototherapy and exchange transfusion. With the lack of standard treatment guidelines it is possible we are either under or over treating a significant number of babies. Although the incidence of kernicterus has decreased dramatically in the last decade it is still known to occur with devastating consequences.

Hyperbilirubinaemia in preterm infants is more prevalent, more severe, and its course more protracted than in term neonates [21-23]. The median time for treatment thresh- 
olds to plateau in our study does not correlate with these physiological facts. Considering these facts we would expect the thresholds to plateau at different times for different gestations. However from our analysis of the results it is clear that this is not the case, median time to plateau is the same for all gestations in the phototherapy group. We expected the median time to plateau to follow an upward or downward trend across the gestations i.e. either lowest or highest for the smaller gestational age. Contrary to our expectations the median time to plateau was lowest for 32 weeks gestation and maximum for term babies with intermediate for 28 weeks gestation in the exchange transfusion group. These findings reflect the fact that the charts which have been followed for years are not evidence based and need reviewing. The fact that treatment of neonatal jaundice can have far reaching positive or sometimes negative consequences makes this all the more important.

Treatment of neonatal jaundice has always been a controversial issue. There have been discussions all over the world about under treatment and over treatment of neonatal jaundice. Phototherapy is a simple method of treatment but has many theoretical risks involved. Exchange transfusion although very effective is potentially life threatening with many serious side effects. Bilirubin levels above a certain level can be harmful, but what is that level at a particular time for a particular gestation? Is kernicterus the only impact of high bilirubin levels or is there any other neurological impact of borderline high bilirubin levels? All these questions need to be addressed before the appropriate threshold for treatment of neonatal jaundice is decided.

As seen in our study there is a wide variation in practice for all the gestational ages studied from 12 to 168 hours. As these charts usually are for a range of gestation we can safely assume the variation to be present for all gestations from 23 weeks to term. Some hospitals were using exclusive charts for each gestational age and some were using formulas. Again there is no evidence supporting the threshold levels considered for treatment from these units.

Hospitals contacted were randomly selected and were not from a specific geographical area. The number of hospitals contacted was 72 out of which 46 responded providing us with 14 to 37 different charts in the various gestational study groups. With the data available from these hospitals the variation in practice is so much that a larger sample size may have further increased the variation. Also the data was randomly collected from units providing various levels of care. Being such a common neonatal problem this should not bias the study.

A larger study was done by Rennie et al. involving around 140 charts from a number of units across UK. Their study demonstrated the wide variation in practice for management of neonatal jaundice and also concluded that there is little existing consensus regarding treatment of neonatal jaundice. Although the study had much larger sample the study does not give a picture of variation from birth to 168 hours of age. We have tried to give a graphical view of the variation in practice in the studied gestational ages till 168 hours of age. We are also emphasizing the possible lack of evidence behind these charts by demonstrating the unexpected trend for the median time for these graphs to plateau. We have not analyzed the bilirubin levels at birth as there is very little evidence behind the levels for treatment at birth.

Jaundice action charts reviewed in our study showed significant variation in the threshold for treatment of neonatal jaundice. Both the studied parameters (variation in threshold and the median time to plateau) point towards the fact that the charts being used in the neonatal units are not evidence based and need modification. There was no reference of evidence quoted in the jaundice action charts surveyed. With the lack of standard treatment guidelines for this common neonatal problem, it is likely that neonatal units are either under or over treating a significant number of babies.

\section{REFERENCES}

[1] T. B. Newman and M. J. Maisels, "Does Hyperbilirubinemia Damage the Brain of Healthy Full-Term Infants?” Clinics in Perinatology, Vol. 17, No. 2, 1990, pp. 331-358.

[2] R. H. Dobbs and R. J. Cremer, "Phototherapy,” Archives of Disease in Childhood, Vol. 50, 1975, pp. 833-836. doi:10.1136/adc.50.11.833

[3] W. J. Cashore and L. Stem, “The Management of Hyperbilirubinemia,” In: A. Zipursky, Ed., Clinics in Perinatology, WB Saunders, Philadelphia, 1984.

[4] I. Abramov, L. Hainline, E. Lemerise and A. K. Brown, "Changes in Visual Functions of Children Exposed as Infants to Prolonged Illumination," Journal of the American Optometric Association, Vol. 56, No. 8, 1985, pp. 614619.

[5] P. Glass, G. B. Avery, S. K. N. Siva, M. P. Keys, A. M. Sostek and D. S. Friendly, "Effect of Bright Light in the Hospital Nursery on the Incidence of Retinopathy of Prematurity," New England Journal of Medicine, Vol. 313, No. 7, 1985, pp. 401-404. doi:10.1056/NEJM198508153130701

[6] V. A. Moyer, C. Ahn and S. Sneed, "Accuracy of Clinical Judgment in Neonatal Jaundice," Archives of Pediatrics \& Adolescent Medicine, Vol. 154, No. 4, 2000, pp. 391394.

[7] R. Tayaba, D. Gribetz, I. Gribetz and I. R. Holzman, 
“Noninvasive Estimation of Serum Bilirubin,” Pediatrics, Vol. 102, No. 3, 1998, p. e28. doi:10.1542/peds.102.3.e28

[8] V. Bhutani, G. R. Gourley, S. Adler, B. Kreamer, C. Dalman and L. H. Johnson, "Noninvasive Measurement of Total Serum Bilirubin in a Multiracial Predischarge Newborn Population to Assess the Risk of Severe Hyperbilirubinemia," Pediatrics, Vol. 106, No. 2, 2000, p. e17. doi:10.1542/peds.106.2.e17

[9] S. Yasuda, S. Itoh, K. Isobe, et al., "New Transcutaneous Jaundice Device with Two Optical Paths," Journal of Perinatal Medicine, Vol. 31, No. 1, 2003, pp. 81-88. doi:10.1515/JPM.2003.012

[10] M. J. Maisels, E. J. Ostrea Jr., S. Touch, et al., "Evaluation of a New Transcutaneous Bilirubinometer," Pediatrics, Vol. 113, No. 6, 2004, pp. 1638-1645. doi:10.1542/peds.113.6.1628

[11] A. P. Hart, "Familial Icterus Gravis of the New-Born and Its Treatment," Canadian Medical Association Journal, Vol. 15, No. 10, 1925, pp. 1008-1011.

[12] P. M. Dunn, "Dr Alfred Hart (1888-1954) of Toronto and Exsanguination Transfusion of the Newborn,” Archives of Disease in Childhood, Vol. 69, No. 1, 1993, pp. 95-96. doi:10.1136/adc.69.1 Spec No.95

[13] W. J. Keenan, K. K. Novak, J. M. Sutherland, D. A. Bryla and K. L. Fetterly, "Morbidity and Mortality Associated with Exchange Transfusion,” Pediatrics, Vol. 75, No. 2, 1985, pp. 417-421.

[14] L. Hovi and M. A. Siimes, "Exchange Transfusion with Fresh Heparinized Blood Is a Safe Procedure: Experiences from 1069 Newborns," Acta Paediatrica Scandinavica, Vol. 74, 1985, pp. 360-365. doi:10.1111/j.1651-2227.1985.tb10984.x

[15] T. R. Boggs and M. C. Westphal, "Mortality of Exchange Transfusion,” Pediatrics, Vol. 26, No. 5, 1960, pp. 745-
755.

[16] J. C. Jackson, “Adverse Events Associated with Exchange Transfusion in Healthy and Ill Newborns,” Paediatrics, Vol. 99, No. 5, May 1997, p. e7. doi:10.1542/peds.99.5.e7

[17] U. John, M. B. Crichton, G. Henry, M. B. Dunn, A. K. McBurney, A.-M. Robertson and E. Tredger, "LongTerm Effects of Neonatal Jaundice on Brain Function in Children of Low Birth Weight," Paediatrics, Vol. 49, No. 5, 1972, pp. 656-670.

[18] L. S. de Vries, S. Lary and L. M. S. Dubowitz, "Relationship of Serum Bilirubin Levels to Ototoxicity and Deafness in High-Risk Low-Birth-Weight Infants,” Pediatrics, Vol. 76, No. 3, 1985, pp. 351-354.

[19] A. L. Gordon, M. English, D. J. Tumaini, M. Karisa, C. R. Newton, "Neurological and Developmental Outcome of Neonatal Jaundice and Neonatal Sepsis in Rural Kenya," Tropical Medicine and Health, Vol. 10, No. 11, 2005, pp. 1114-1120. doi:10.1111/j.1365-3156.2005.01496.x

[20] R. K. Kumar, "Neonatal Jaundice. An Update for Family Physicians,” Australian Family Physician, Vol. 28, No. 7 , 1999, pp. 679-682.

[21] B. H. Billing, P. G. Cole and G. H. Lathe, "Increased Plasma Bilirubin in Newborn Infants in Relation to Birth Weight,” British Medical Journal, Vol. 2, No. 4899, 1954, pp. 1263-1265. doi:10.1136/bmj.2.4899.1263

[22] R. C. Harris, "Peak Levels of Serum Bilirubin in Normal Premature Infants,” In: A. Sass-Kortsak, Ed., Kernicterus, University of Toronto Press, Toronto, 1961, pp. 10-12.

[23] J. F. Watchko, "The Clinical Sequelae of Hyperbilirubinemia,” In: M. J. Maisels and J. F. Watchko, Eds., Neonatal Jaundice, Harwood Academic Publishers, Amsterdam, 2000, pp. 115-135. 